\title{
INFLUENCE OF COOLING CONDITIONS ON A SLAB’S CHILL ZONE FORMATION DURING CONTINUOUS CASTING OF STEEL
}

\begin{abstract}
The cooling conditions of a slab during continuous casting of steel have an impact on the crystalline structure formation. Numerical methods allow real processes to be modelled. Professional computer programs are available on the market, so the results of their simulations allow us to understand the processes that occur during the casting and solidification of the slab. The study attempts to evaluate the impact of the intensity of the secondary cooling on the chilled zone size. The calculations show the differences in the structure of a slab cast with various speeds while maintaining industrial cooling parameters during operation of a continuous casting machine.
\end{abstract}

Keywords: crystallisation, chilled grains, continuous casting of steel, ProCAST

\section{Introduction}

The cast strand macrostructure is largely related to the casting temperature (superheat), strand geometry, cooling and steel composition. Usually, cast strands have a fine equiaxed zone near the surface (the chilled grain zone). This zone forms during a fast crystallisation beginning. Depending on the casting parameters, the central area usually solidifies as a combination of columnar dendrites from the chilled grain zone towards the centre of the strand and equiaxed dendrites in the central part of the slab. When the superheat temperature is very high, the equiaxed zone may not exist, so the macrostructure is comprised of columnar dendrites entirely. When the superheat is very low, the slab may solidify with the equiaxed dendrite zone only. The equiaxed zone can consist of randomly oriented dendrites or can have a globular structure. When the macrostructure consists of columnar and equiaxed grains, then a columnar-toequiaxed transition (CET) occurs. The CET transition in a slab often involves a negative effect of segregation, the so-called white bands, which may appear when electromagnetic stirring is applied [1-2]. Figure 1 shows a typical steel slab structure diagram, divided into zones of chilled, columnar and equiaxed grains.

On the basis of numerical calculations in the ProCAST software, the paper determines the influence of secondary cooling intensity on the size of the forming chill zone in a continuously cast slab intended for flat products. The computations allowed us to indicate differences in the structure of a slab cast with various speeds, while maintaining industrial cooling conditions during operation of the continuous caster.

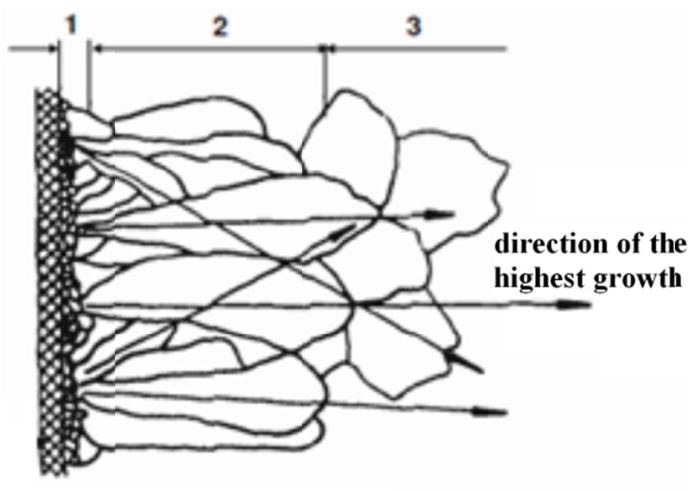

a)

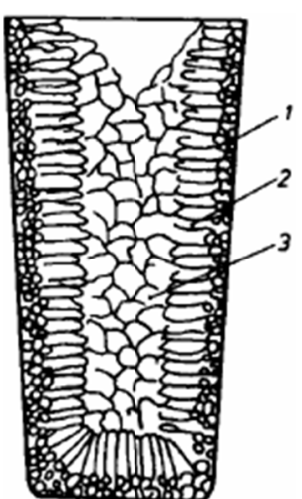

b)

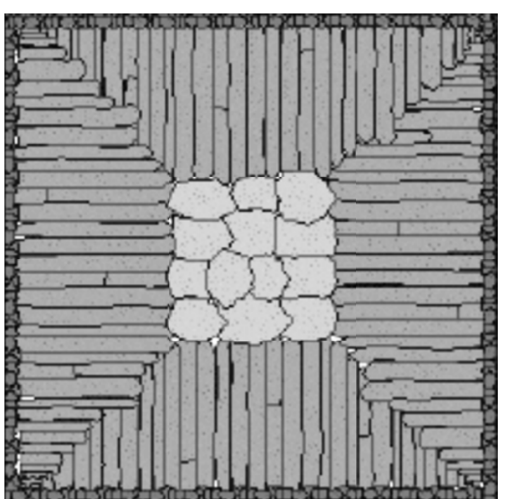

c)

Fig. 1. Steel slab structure diagram. a), b) 1 - chill zone; 2 - columnar zone; 3 - equiaxed zone, c) cross-section perpendicular to the slab axis [3]

\footnotetext{
AGH UNIVERSITY OF SCIENCE AND TECHNOLOGY, FACULTY OF METALS ENGINEERING AND INDUSTRIAL COMPUTER SCIENCE, AL. A. MICKIEWICZA 30, 30-059 KRAKÓW, POLSKA Corresponding author: pdrozdz@agh.edu.pl
} 


\section{Cooling zones in the continuous steel casting process}

Steel solidification in the process of continuous casting starts within the mould, which constitutes the primary cooling zone, and subsequently it is continued in the water spray or air-mist spray zone located within the secondary cooling chamber. After leaving the chamber the strand is cooled with air and partially with guide rolls. The mould is built of copper slabs, which are intensively water-cooled. The slabs form the internal shape of the cross-section of the working part of the mould, which is adjustable to give the required dimensions to the cast strand. During cooling in the mould, a solidified strand layer - the shell - forms. Its strength and thickness are the basic parameters of the continuous casting process. The main task of the secondary cooling zone is to continue the solidification of the strand leaving the mould. The secondary cooling system comprises a few separate zones in which the strand cooling intensity can be controlled. The slab quality, in particular the quality of their surface and macrostructure, depends on the operation of the secondary cooling zone.

The distance that is covered by the steel from the metal meniscus in the mould to the exit from the last segment of strand carrying rolls is called the metallurgical length. In this study, a slab with a cross-section $220 \mathrm{~mm} \times 1600 \mathrm{~mm}$, cast on an arc-shaped continuous caster with a radius of $10500 \mathrm{~mm}$, characterised by a metallurgical length of $23296 \mathrm{~mm}$, was analysed. The strand length to the strand straightening point is $18103 \mathrm{~mm}$, whereas to the point of exit from the secondary cooling chamber it is 18438 $\mathrm{mm}$. The mould is cooled with a constant cooling intensity, independent of the casting speed. The secondary cooling is divided into 7 zones, and their cooling intensity depends on the casting speed. In addition, the secondary cooling intensity, by selecting an appropriate cooling schedule, depends on the steel grade that is on the carbon and alloy contents. Table 1 presents the area of all slab cooling zones, whereas Figure 2 shows the change in the secondary cooling intensity versus the casting speed for a selected cooling schedule.

TABLE 1

Strand cooling zone in the continuous strand casting process broken down into all zones

\begin{tabular}{|c|c|}
\hline Cooling zone & Surface, $\mathbf{~}^{\mathbf{2}}$ \\
\hline Mould & 2.91 \\
\hline $1^{\text {st }}$ zone & 0.94 \\
\hline $2^{\text {nd }}$ zone & 0.52 \\
\hline $3^{\text {rd }}$ zone & 5.87 \\
\hline $4^{\text {th }}$ zone & 11.80 \\
\hline $5^{\text {th }}$ zone & 13.28 \\
\hline $6^{\text {th }}$ zone & 13.31 \\
\hline $7^{\text {th }}$ zone & 10.70 \\
\hline Air cooling zone & 21.44 \\
\hline
\end{tabular}

\section{Heat transfer coefficients $\alpha$}

Secondary cooling is performed with nozzles supplied either with water or with air-mist. The density of heat flux exchanged between the strand and the coolant in the area of water stream impact is heterogeneous, and therefore in many cases empirical dependences are assumed for computing. They take into account the most important parameters decisive to the cooling intensity, arising from the nozzle design, cooling water stream density, its

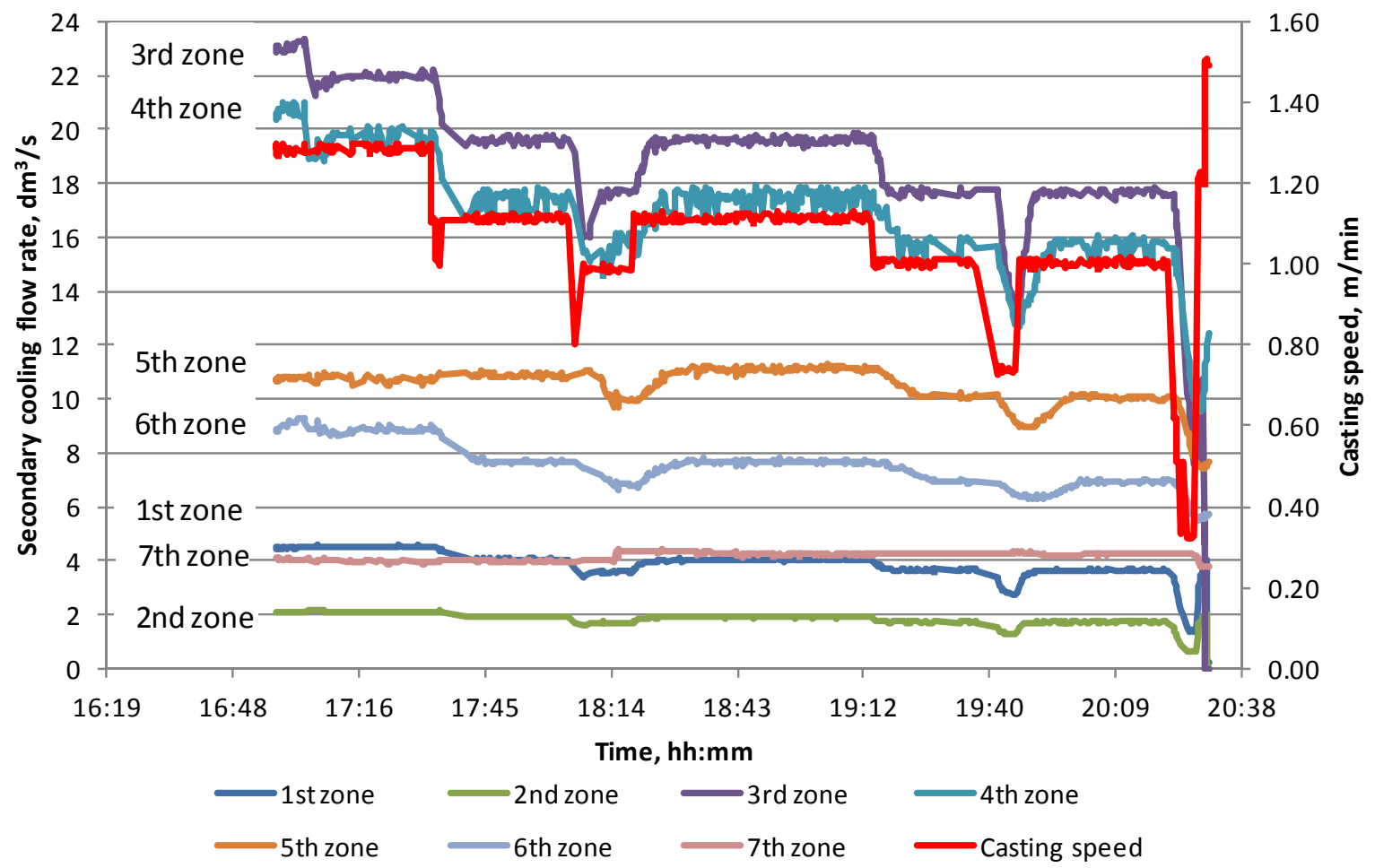

Fig. 2. The change in secondary cooling intensity versus casting speed for a selected cooling schedule 
pressure and speed. The heat flux densities, and thus the heat transfer coefficients depend on the temperature of the strand surface and the cooling water temperature. The distance of the cooling nozzle outlet to the strand surface is an important factor [4-5]. In the actual continuous steel casting process, depending on the cooling intensity, individual cooling zones may be characterised by a diversified heat transfer average value $\alpha_{\text {spray }}$ expressed in $\mathrm{W} / \mathrm{m}^{2} / \mathrm{K}$ calculated on the basis of the simplified formula (1) [6]:

$$
\alpha_{\text {spray }}=10 v+(107+0.688 v) \dot{V}_{\text {spray }}
$$

where:

$v$ - water drop speed, $\mathrm{m} / \mathrm{s}$, $\dot{V}_{\text {spray }}$ - water stream density, $\mathrm{m}^{3} / \mathrm{s} / \mathrm{m}^{2}$.

This formula allows the heat transfer coefficient values to be estimated, when the surface temperature is unknown. The value of the water stream density $\dot{V}_{\text {spray }}$, and the speed of water drops $v$ falling onto the strand surface cooled need to be estimated. The value of the water stream density was calculated knowing the secondary cooling zone area and the water flow rate on the basis of the formula (2):

$$
\dot{V}=\frac{V}{S_{\text {zone }}}
$$

where:

$V$ - water flow rate, $\mathrm{m}^{3} / \mathrm{s}$, $S_{\text {zone }}$ - zone area, $\mathrm{m}^{2}$.

The strand withdrawal speed during the process of steel casting varies, which forces a change in the cooling parameters resulting in a change in the spray flow rate. The spray water flows through the same nozzles all the time. Therefore the speed of the water drops outflow from a nozzle can be calculated on the basis of the formula (3):

$$
v=\frac{V}{S_{\text {nozzle }}}
$$

where: $S_{\text {nozzle }}$ - nozzle cross-section area, $\mathrm{m}^{2}$.

Table 2 presents the speed of the water drop outflow from a nozzle for the selected strand withdrawal speeds, after taking

TABLE 2

The speed of the water drop outflow from a nozzle for the selected strand withdrawal speeds

\begin{tabular}{|c|c|c|c|}
\hline \hline Casting speed, $\mathbf{~ m} / \mathbf{m i n}$ & $\mathbf{0 . 8}$ & $\mathbf{1 . 0}$ & $\mathbf{1 . 2}$ \\
\hline Cooling zone & \multicolumn{2}{|c|}{ The speed of the water drop $\boldsymbol{v} \mathbf{~} \mathbf{~} / \mathbf{s}$} \\
\hline $1^{\text {st }}$ zone & 21.3 & 26.4 & 30.6 \\
\hline $2^{\text {nd }}$ zone & 20.3 & 25.1 & 29.2 \\
\hline $3^{\text {rd }}$ zone & 23.4 & 28.4 & 33.3 \\
\hline $4^{\text {th }}$ zone & 10.3 & 12.5 & 14.6 \\
\hline $5^{\text {th }}$ zone & 10.8 & 13.2 & 15.5 \\
\hline $6^{\text {th }}$ zone & 9.3 & 11.3 & 13.3 \\
\hline $7^{\text {th }}$ zone & 11.6 & 16.5 & 18.6 \\
\hline
\end{tabular}

The chemical composition of the steel taken into account in computing into account the actual water flow rate in each secondary cooling zone. However, Table 3 presents the calculated average values of heat transfer coefficients $\alpha$ for the narrow and wide side of the slab after taking into account all cooling zones. The heat transfer coefficient values $\alpha$ for the mould and for air cooling are taken from literature. The calculated values will be used as boundary conditions for modelling the temperature distribution on the strand using numerical methods in the ProCAST software.

TABLE 3

\begin{tabular}{|c|c|c|c|c|}
\hline \multicolumn{2}{|c|}{ Casting speed, $\mathrm{m} / \mathrm{min}$} & 0.8 & 1.0 & 1.2 \\
\hline \multicolumn{2}{|c|}{ Cooling zone } & \multicolumn{3}{|c|}{ Heat transfer coefficients $\alpha, \mathrm{W} / \mathrm{m}^{2} / \mathrm{K}$} \\
\hline \multirow{8}{*}{ 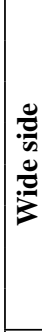 } & Mould & 1600 & 1600 & 1600 \\
\hline & $1^{\text {st }}$ zone & 550 & 694 & 819 \\
\hline & $3^{\text {rd }}$ zone & 501 & 616 & 733 \\
\hline & $4^{\text {th }}$ zone & 213 & 260 & 307 \\
\hline & $5^{\text {th }}$ zone & 170 & 210 & 247 \\
\hline & $6^{\text {th }}$ zone & 136 & 166 & 196 \\
\hline & $7^{\text {th }}$ zone & 145 & 208 & 236 \\
\hline & Air cooling zone & 85 & 85 & 85 \\
\hline \multirow{8}{*}{ 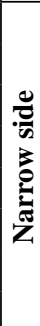 } & Mould & 1600 & 1600 & 1600 \\
\hline & $2^{\text {nd }}$ zone & 490 & 615 & 724 \\
\hline & $3^{\text {rd }}$ zone & 501 & 616 & 733 \\
\hline & $4^{\text {th }}$ zone & 213 & 260 & 307 \\
\hline & $5^{\text {th }}$ zone & 170 & 210 & 247 \\
\hline & $6^{\text {th }}$ zone & 136 & 166 & 196 \\
\hline & $7^{\text {th }}$ zone & 145 & 208 & 236 \\
\hline & Air cooling zone & 85 & 85 & 85 \\
\hline
\end{tabular}

The average values of heat transfer coefficients $\alpha$ for the narrow and wide side of the strand cast

\section{ProCAST - thermal mode}

Nowadays, advanced computer programs are used for numerical modelling of the continuous steel casting process [7]. The ProCAST software package is a solution, which allows computing of casting processes to be performed with the finite element method. Results of simulations in the ProCast software include temperature distribution, strand metallurgical length and shell thickness. The advantages of numerical modelling allow these methods to be applied to effectively design new casting technologies and to optimise existing ones.

The thermal model of the steel continuous casting process for slabs was formulated on the basis of the actual process engineering parameters. To this end, the slab geometry was prepared, taking into account the division into the existing cooling zones. The same steel grade with the chemical composition presented in Table 4 was assigned to all strand elements.

TABLE 4

\begin{tabular}{|c|c|c|c|c|c|c|c|c|c|}
\hline \hline Al, \% & C, \% & Cr, \% & Cu, \% & Mn, \% & N, \% & Ni, \% & P, \% & S, \% & Si, \% \\
\hline 0.0282 & 0.0966 & 0.0209 & 0.0222 & 0.736 & 0.0053 & 0.0731 & 0.0126 & 0.0105 & 0.0184 \\
\hline
\end{tabular}


After entering the steel chemical composition into the ProCAST program, the material data of the steel grade concerned was computed and then verified and adjusted. The material data includes thermophysical properties, such as: thermal conductivity, density, enthalpy, solid fraction share and the liquidus and solidus temperatures. The specific heat, along with the melting heat of the material used in computations, are amongst more essential properties. After assigning the appropriate material to each part of the model, along with the verified material data, the boundary conditions and initial conditions for the specific process were determined. The prepared geometric model with the FEM mesh applied, with declared boundary and initial conditions, constitutes a complete data set allowing the simulation to be performed. The computations resulted in obtaining the temperature distribution on the whole strand length versus the casting speed. Table 5 presents a summary of the simulation results in the thermal model for various casting speeds. Figure 3 shows the selected points on the $1 / 4$ of the cross-section of the strand cast; these points were used for plotting the temperature distribution. Figures 4-6 present the temperature distribution at the selected points along the whole strand length versus the casting speed.

TABLE 5

The summary of simulation results in the thermal model for various casting speeds

\begin{tabular}{|c|c|c|c|c|c|}
\hline Casting speed, $\mathbf{m} / \mathbf{m i n}$ & Casting time, $\mathbf{s}$ & $\begin{array}{c}\text { Total solidification } \\
\text { time, s }\end{array}$ & $\begin{array}{c}\text { Length of the liquid } \\
\text { core, } \mathbf{~ m m}\end{array}$ & $\begin{array}{c}\text { Time of staying } \\
\text { within the mould, s }\end{array}$ & $\begin{array}{c}\text { Shell thickness under } \\
\text { the mould, } \mathbf{m m}\end{array}$ \\
\hline 0.8 & 1843 & 1036 & 13810 & 59 & 24 \\
\hline 1.0 & 1467 & 1027 & 17120 & 47 & 20 \\
\hline 1.2 & 1255 & 996 & 19920 & 40 & 18 \\
\hline
\end{tabular}

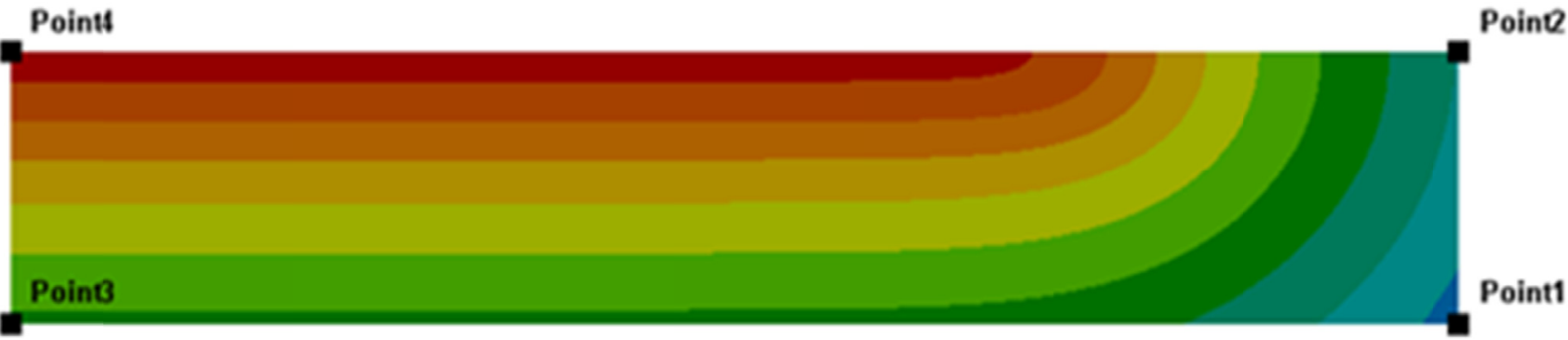

Fig. 3. Selected points at $1 / 4$ of the strand cross-section. Point 1 - slab corner, Point 2 - centre of the slab narrow side, Point 3 - centre of the wide side, Point 4 - slab centre

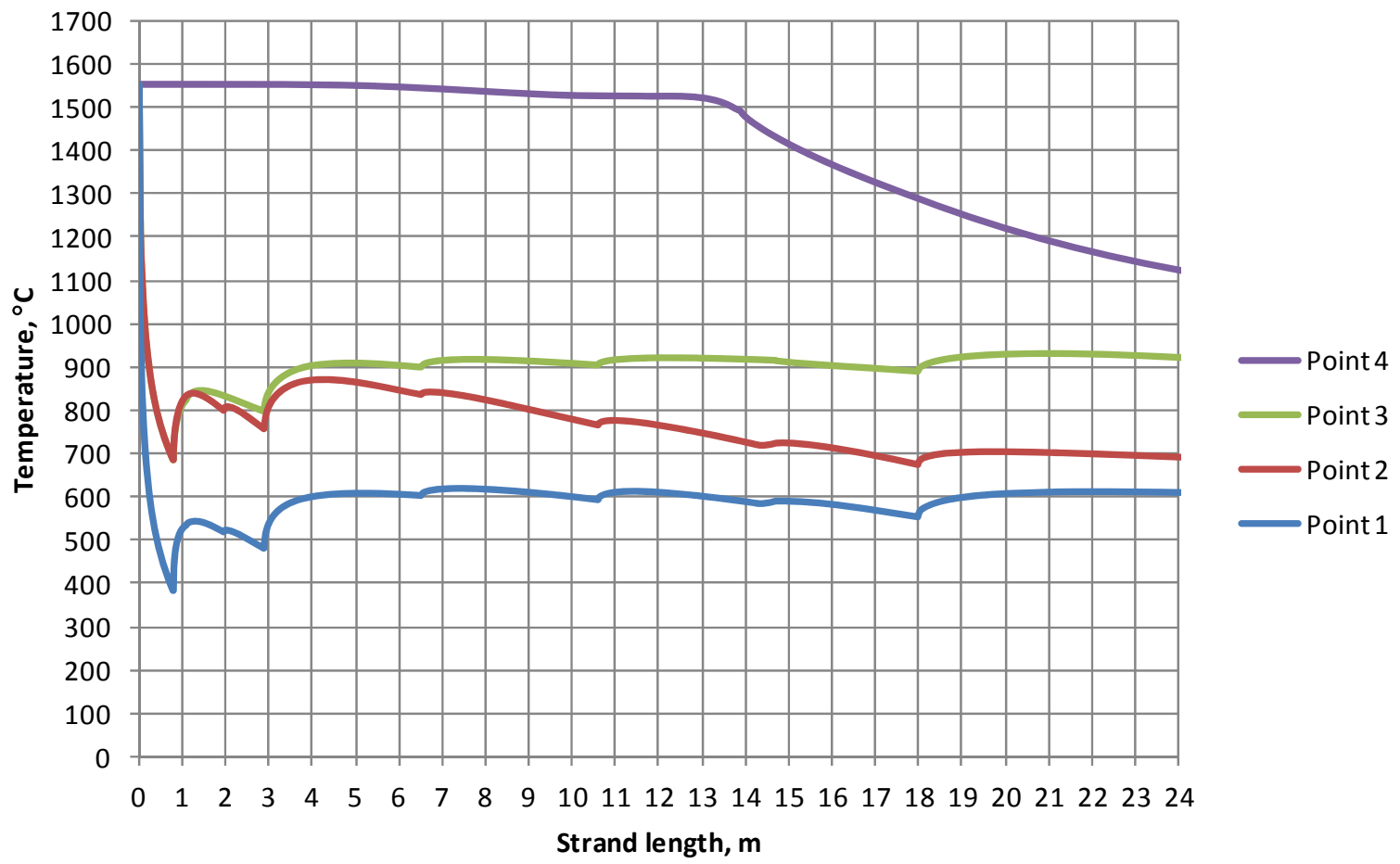

Fig. 4. The temperature distribution at the selected points along the whole strand length for the casting speed $\mathrm{V}=0.8 \mathrm{~m} / \mathrm{min}$ 


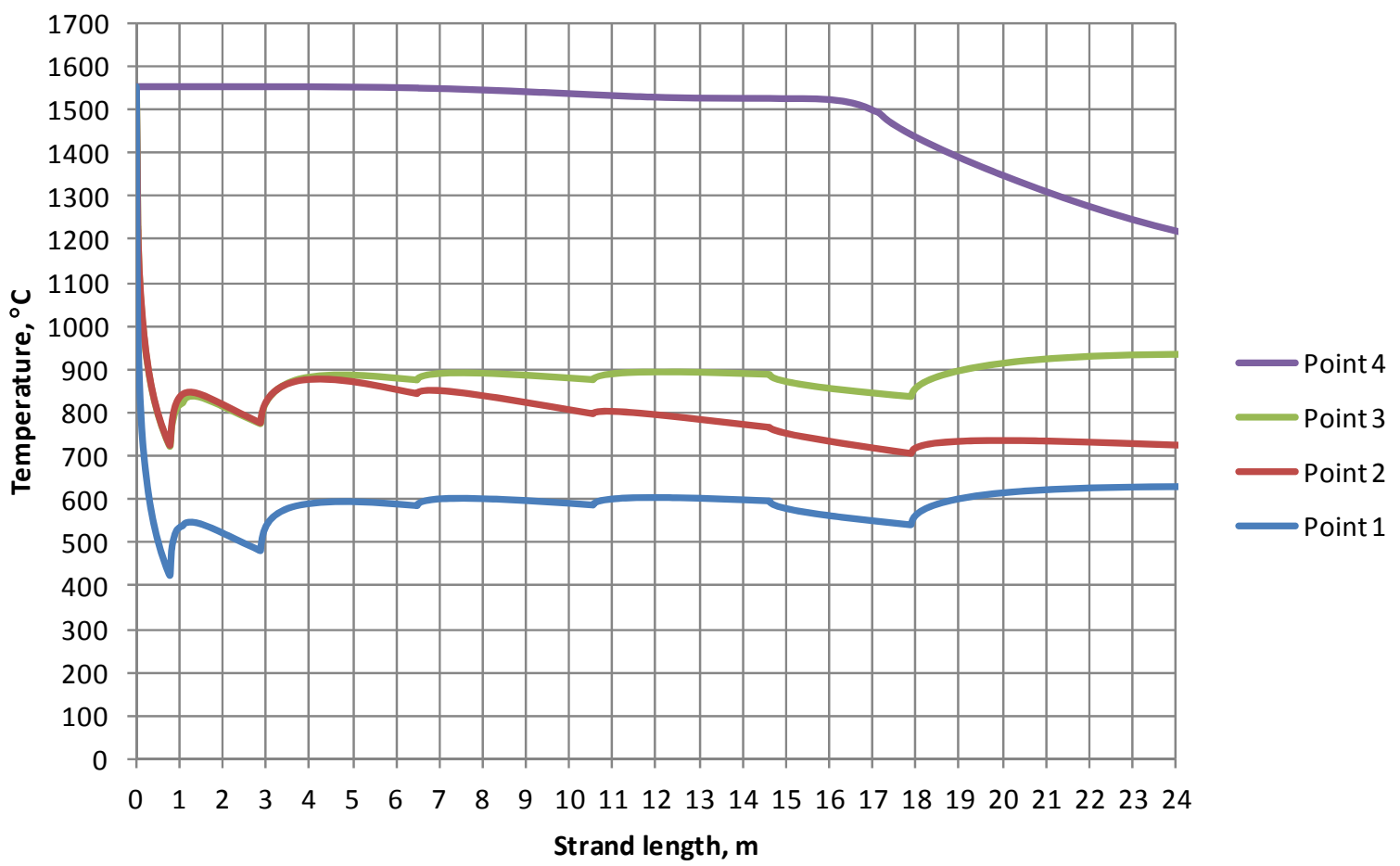

Fig. 6. The temperature distribution at the selected points along the whole strand length for the casting speed V=1.0 $\mathrm{m} / \mathrm{min}$

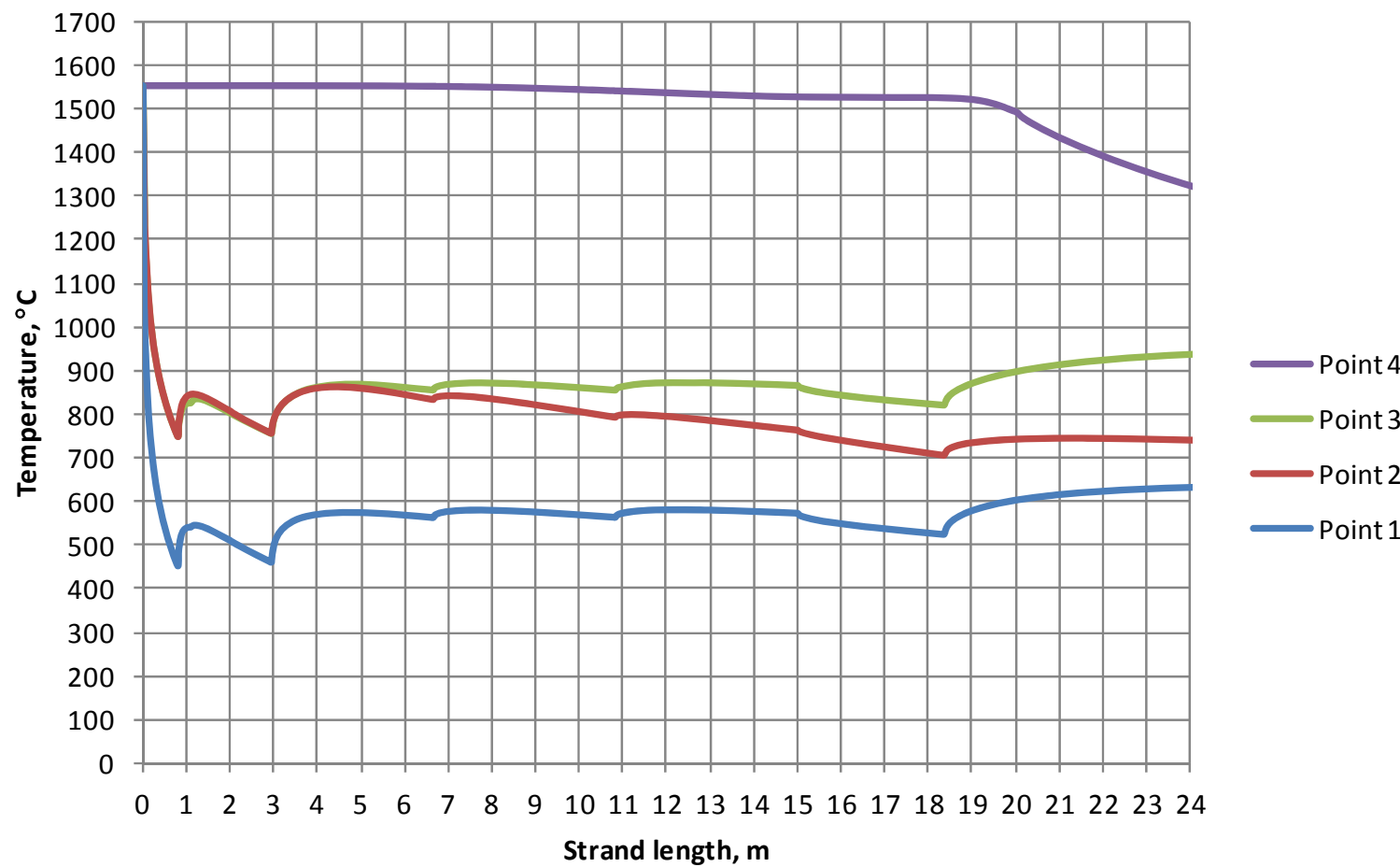

Fig. 6. The temperature distribution at the selected points along the whole strand length for the casting speed $\mathrm{V}=1.2 \mathrm{~m} / \mathrm{min}$

Steel casting and cooling in the continuous casting process during one sequence should enable a slab with a consistent quality to be obtained regardless of the casting speed. For various logistic reasons in a steel production cycle, the casting speed is altered, in order to maintain the casting continuity, which involves a change in the strand cooling intensity. Despite these changes, a slab should feature similar values as regards the length of the liquid core, the shell thickness and the temperature distribution along the whole strand length. These properties are related to the design parameters of the continuous caster, and maintaining them at an appropriate level ensures the casting process is failure free. Too thin a shell under the mould can result in a breakout and spillage of the liquid steel onto rolls. The strand should fully solidify before shearing. On the other hand, the length of the liquid core should not be shorter than the strand length upstream straightening; when the soft reduction system 
is applied it should be closely related to this system. Numerical computing in the thermal model, illustrated by the selected steel grade, taking into account actual process parameters, show certain differences in results as the casting speed changes. An increase in the shell thickness under the mould is observed as the casting speed decreases. Assuming a constant mould cooling intensity, this relationship is as expected. It was observed that when the cooling intensity in the secondary cooling zone and the casting speed decreased, the liquid core length changed, which was directly related to the different temperatures of the strand centre along the strand for various casting speeds. The strand surface features a similar temperature regardless of the casting speed, which may show that the casting parameters in the actual process are selected correctly.

\section{ProCAST - the CAFE model}

Attempts to model processes of formation of the slab structure, taking nucleation and grain growth into account, are available in literature [8-11]. Numerical models consider the heat flow issue in the scale of the whole strand, whereas nucleation and grain growth in the micro scale. Unfortunately, in some models it is not possible to determine the columnar zone boundaries and the relationships between the length and the cross-section of grains. The CAFE model, which is now available as a ProCAST software module, was used in this study to describe the nucleation and grain growth of the primary phase. In this model cellular automata (CA) were used. The cellular automaton method enables the grain nucleation on the strand surface and within its volume to be simulated and the growth of individual primary phase grains to be analysed. The modelling results in the history of changes of the interface position, and the determination of the grain boundaries after completion of strand solidification. The CA method computations are coupled with the simulation of the strand temperature field. The nucleation at the strand surface and within its volume is heterogeneous with random distribution of nuclei. It is assumed that the dependence of the amount of active nuclei on superheat is described by the Gauss normal distribution function with the mean $\Delta T_{\mu}$ and the standard deviation $\Delta T_{s}$. The values of surface and volumetric nuclei density assumed in the modelling, and the Gauss function parameters used in the model, are presented in Table 6.

TABLE 6

Nucleation parameters assumed in the modelling

\begin{tabular}{|c|c|}
\hline \multicolumn{2}{|c|}{ Volume nucleation } \\
\hline Average undercooling, $\Delta T_{\mu}$ & 22 \\
\hline Standard deviation, $\Delta T_{S}$ & 6 \\
\hline Maximum number of nuclei, $N$ max, $\mathrm{m}^{-2}$ & 200000 \\
\hline Surface nucleation \\
\hline Average undercooling, $\Delta T_{\mu}$ & 15 \\
\hline Standard deviation, $\Delta T_{S}$ & 9 \\
\hline Maximum number of nuclei, $G \mathrm{max}, \mathrm{m}^{-3}$ & 650000 \\
\hline
\end{tabular}

The slab structure in the cross-section obtained by the simulation with a cellular automaton is presented in Figure 7. A narrow equiaxed chill zone is located near the slab surface. In the case analysed, the equiaxed zone in the central part is

a)

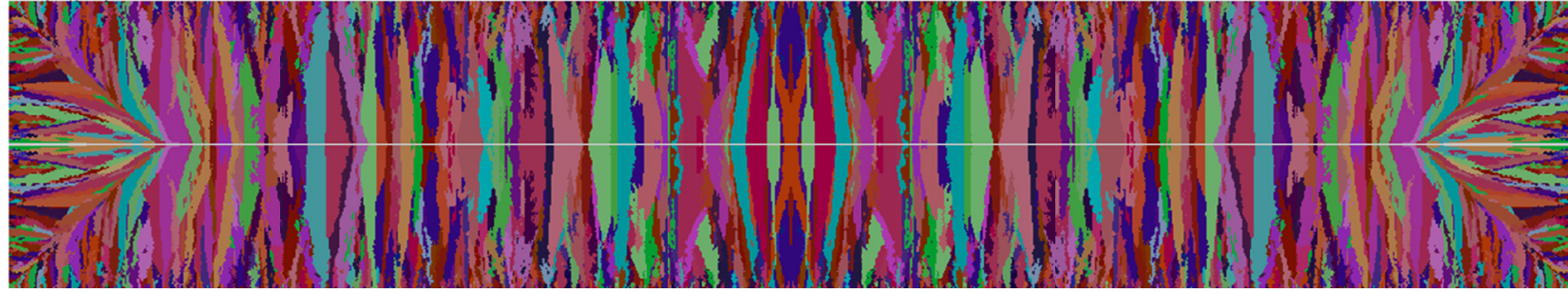

b)

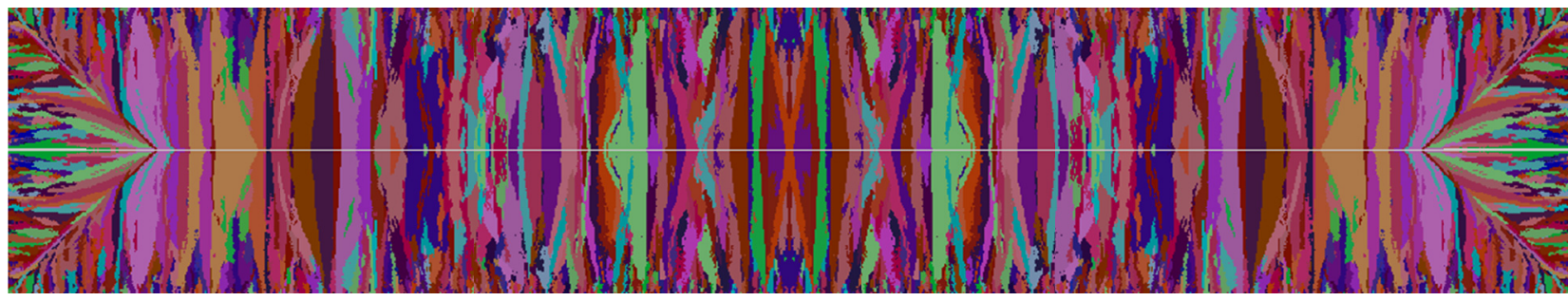

c)

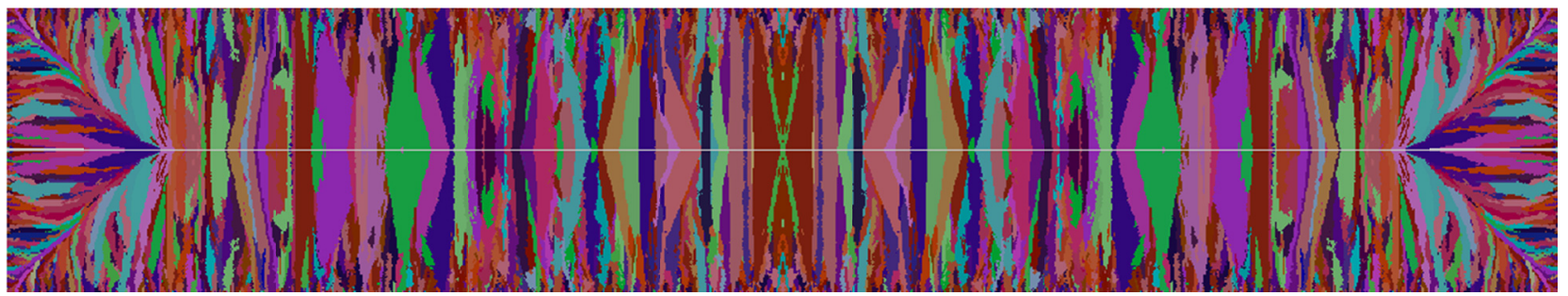

Fig. 7. Results of modelling of the primary grain structure in the cross-section of a steel strand with dimensions of $220 \mathrm{x} 1600 \mathrm{~mm}$ for various casting speeds: a) $V=0.8 \mathrm{~m} / \mathrm{min}$, b) $V=1.0 \mathrm{~m} / \mathrm{min}$, c) $\mathrm{V}=1.2 \mathrm{~m} / \mathrm{min}$ 


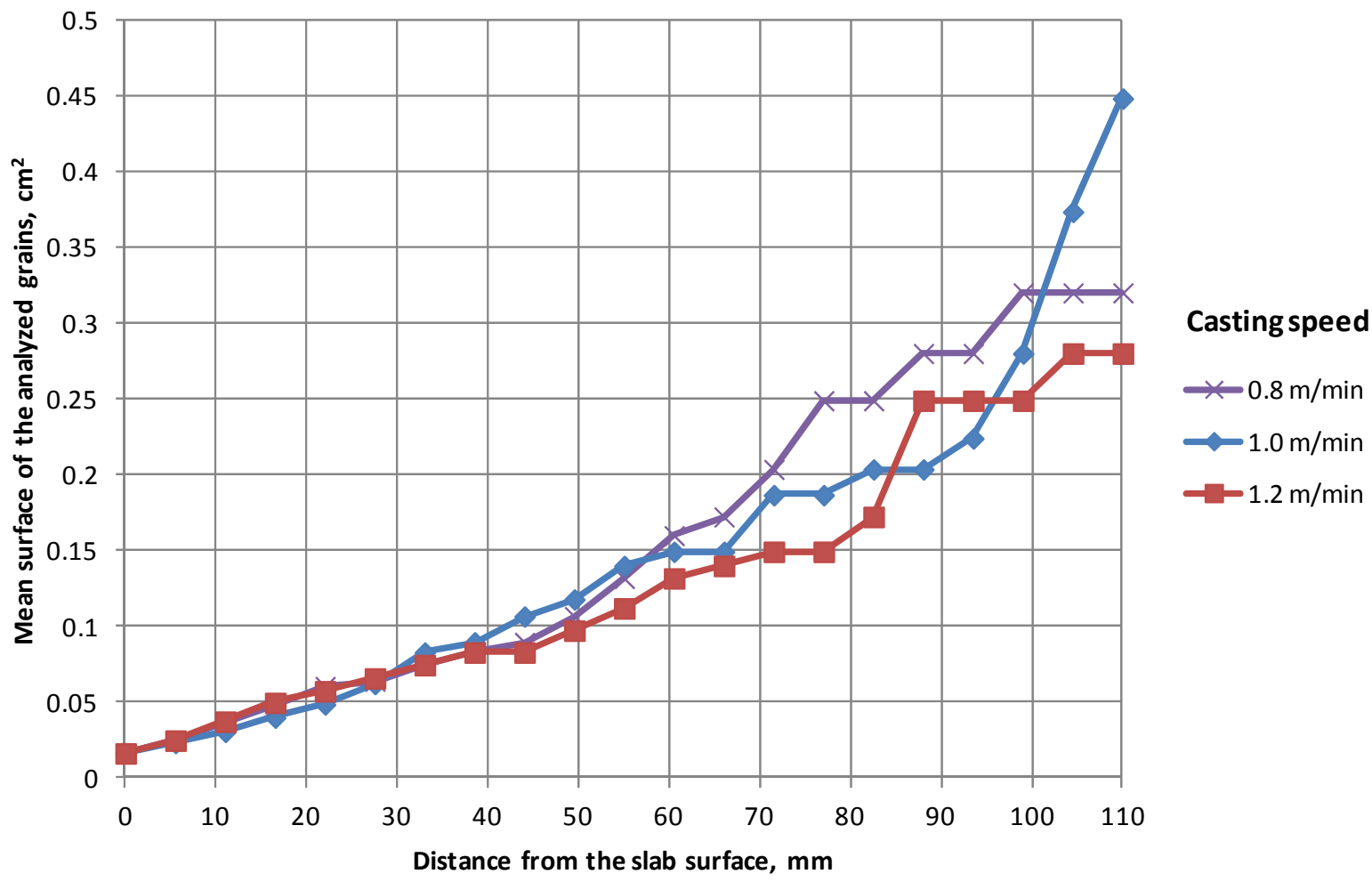

Fig. 8. The change in the mean surface of analyzed grains in the slab cross-section versus casting speed

practically non-existent. The columnar zone dominates the whole cross-section. Figure 8 presents the change in the mean surface of analyzed grains in the slab cross-section versus the casting speed. An increase in the casting speed slightly influences obtaining a finer strand structure. A similar structure may exist in slabs.

The results of the modelling of the slab structure obtained with the CAFE method may reproduce well the actual structure of the slabs obtained by continuous casting. However, they do not allow some defects, such as e.g. axial porosity, to be forecast.

\section{Conclusion}

The CAFE module of the ProCAST software is a useful tool for modelling the formation of the structure of slabs obtained by continuous casting. In accordance with the results of modelling the solidification process of a slab with a cross-section of $220 \times 1600 \mathrm{~mm}$, a structure was obtained, which consists of a narrow equiaxed chill zone and a wide columnar zone. The equiaxed zone in the central part is practically non-existent. An increase in the casting speed with a simultaneous increase in the secondary cooling intensity involves a change in strand solidification conditions. A change in the cooling intensity taking into account the local industrial conditions results in obtaining a liquid core in the strand with various lengths, whereas the temperature distribution at the strand surface shows slight differences. An increase in the casting speed causes a slight grain size reduction at the strand cross section.
Acknowledgements

The study was funded from the means of the Ministry of Science and Higher Education as a statutory work of AGH-UST No 11.11.110293.

\section{REFERENCES}

[1] T. Pikkarainen, V. Vuorenmaa, I. Rentola, M. Leinonen, D. Porter, Effect of superheat on macrostructure and macrosegregation in continuous cast low-alloy steel slabs. 4th International Conference on Advances in Solidification Processes (ICASP-4), Materials Science and Engineering 11 (2016).

[2] Liang Bai, Bo Wang, Honggang Zhong, Jie Ni, Qijie Zhai, Jieyu Zhang, Experimental and Numerical Simulations of the Solidification Process in Continuous Casting of Slab. Metals 6, 53 (2016).

[3] Z. Kudliński, Technologie odlewania stali. Wydawnictwo Politechniki Śląskiej, Gliwice, 2006.

[4] K. Milkowska-Piszczek, J. Falkus, Calculation of the boundary conditions in the continuous casting of steel process. Metalurgija 53, 4, 571-573 (2014).

[5] Z. Malinowski, M. Rywotycki, Modelling of the strand and mold temperature in the continuous steel caster, Archives of Civil and Mechanical Engineering 9 (2), 59-73 (2009).

[6] A. Buczek, A. Burbelko, P. Drożdż, M. Dziarmagowski, J. Falkus, M. Karbowniczek, Tomasz Kargul, K. Miłkowska-Piszczek, M. Rywotycki, K. Sołek, W. Ślęzak, T. Telejko, L. Trębacz, E. Wielgosz, Modelowanie procesu ciagłego odlewania stali monografia, Radom 2012. 
[7] B. Thomas, Modeling of the Continuous Casting of Steel- Past, Present and Future. Electric Furnace Conference Proceedings, ISS 59, 3-30. (2001).

[8] A. Burbelko, J. Falkus, W. Kapturkiewicz, K. Sołek, P. Drożdż, M. Wróbel, Modeling of the grain structure formation in the steel continuous ingot by CAFE method. Archives of Metallurgy and Materials, Polish Academy of Sciences. Committee of Metallurgy. Institute of Metallurgy and Materials Science 57, 1, 379-384 (2012).
[9] M. Rappaz, Ch.-A. Gandin, Probabilistic modeling of microstructure formation in solidification process. Acta Metallurgica et Materialia 41, 2, 345-360 (1993).

[10] Ch.-A. Gandin, M Rappez, A coupled finite element-cellular automation model for the prediction of dendritic grain structures in solidification processes. Acta Metallurgica et Materialia, 42, 7, 2233-2246 (1994).

[11] Ch.-A. Gandin, J.-L. Desbiolles, M. Rappaz, Ph. Thevoz: A three-dimensional cellular automation - finite element model for the prediction of solidification grain structures. Metallurgical and Materials Transactions A 30, 3153-3165, December (1999). 